\title{
Acute Glomerulonephritis in Middle-aged and Elderly Patients
}

\author{
H. A. LEE,* M.B., B.SC., M.R.C.P.; G. STIRLING, † M.D., M.C.PATH. ; P. SHARPSTONE, $\ddagger$ M.B., M.R.C.P.
}

[With Special Plate]

Brit. med. F., 1966, 2, 1361-1363

Acute glomerulonephritis is an uncommon disease in the middle-aged and elderly. Of the 173 cases investigated by Ellis (1942) only three were over 50 and none was over 60 ; and Fishberg (1954) reported only once seeing a patient older than 60. While acute glomerulonephritis may pursue a malignant course-with death from oliguric renal failure in the acute phase, at any age-older patients seem particularly prone to this severe variant of the disease. Further, in this age group the presenting features often differ from those commonly seen in younger patients (Samiy, Field, and Merrill, 1961).

It is for these reasons that we report the clinical and pathological features of the seven patients aged over 50 seen at the renal unit of King's College Hospital in a three-year period from 1962 to 1965 . They were all referred from other hospitals because of renal failure severe enough to warrant consideration of haemodialysis. During this time no younger patient with this disease required haemodialysis at this unit.

\section{Clinical and Pathological Features}

Table I summarizes the main clinical features of the patients, whose ages ranged from 53 to 78 .

The commonest presenting symptoms were non-specific and included anorexia, nausea, vomiting, and diarrhoea. In only two patients was the onset of the illness preceded by a sore throat, and they both had high antistreptolysin-O (A.S.O.) titres. In two of the other three patients in whom the test was carried out the A.S.O. titre was 200 units or above. In no case were streptococci cultured from throat swabs. Three patients had non-dependent oedema, only two had hypertension, and macroscopic haematuria featured at some stage of the illness in five cases. Most of the patients were aware of a reduction in urine volume before admission, and anuria supervened in five of them in the terminal stages.

The initial clinical diagnoses were correct in only three patients. Obstruction of the renal tract, renal vascular acci-

- Lecturer in Medicine, King's College Hospital Medical School, London. Present address: University Department of Medicine, the Royal Infirmary, Manchester 13.

t Senior Lecturer and Consuitant in Morbid Anatomy, King's College Hospital and Medical School, London. ¥ Registrar, Medical Unit, King's College Hospital, London. dent, and exacerbation of chronic renal failure were the most frequently considered alternatives, and retrograde pyelography was carried out in five of the patients.

Treatment was with an acute oliguric renal failure regimen, and anabolic steroids were given to all. Hyperkalaemia was treated, when necessary, with oral or rectal Resonium-A. Haemodialysis with the Kolff twin-coil artificial kidney was carried out on four of the patients on one or two occasions. Only one (Case 1) received corticosteroids. Percutaneous renal biopsy specimens were obtained with the Menghini needle in four patients.

All seven patients died from anuric or oliguric renal failure, or its complications, 15 days to 17 weeks after the onset of the illness.

Details of the renal histology are presented in Table II. In no case was there any disease with which a glomerulitis may be associated, such as polyarteritis nodosa, systemic lupus erythematosus, or subacute bacterial endocarditis.

\section{Discussion}

Samiy et al. (1961) have drawn attention to the unusual features of acute glomerulonephritis in older patients, and this has been our experience too. Only two patients had a typical presentation with a sore throat followed by haematuria, oedema, and hypertension, permitting a fairly confident clinical diagnosis of acute glomerulonephritis to be made. In the others the presenting symptoms gave no clue to the cause of the acute renal failure. Because of anuria, obstruction of the urinary tract was suspected in five of the patients, and retrograde pyelography was performed.

Although fatal anuric glomerulonephritis may occur at any time of life (Berlyne and Baker, 1964 ; Harrison, Loughridge, and Milne, 1964), the age range of our patients emphasizes the predilection for the older age groups of this form of the disease. Other reports confirm this. In a post-mortem study by Nesson and Robbins (1960) of 23 patients who died of acute glomerulonephritis 12 were aged over 50. In Berlyne and Baker's (1964) report of eight patients with fatal glomerulonephritis two were over 50, and no patient older than 40 survived in the series of patients of Harrison et al. (1964) with oliguric

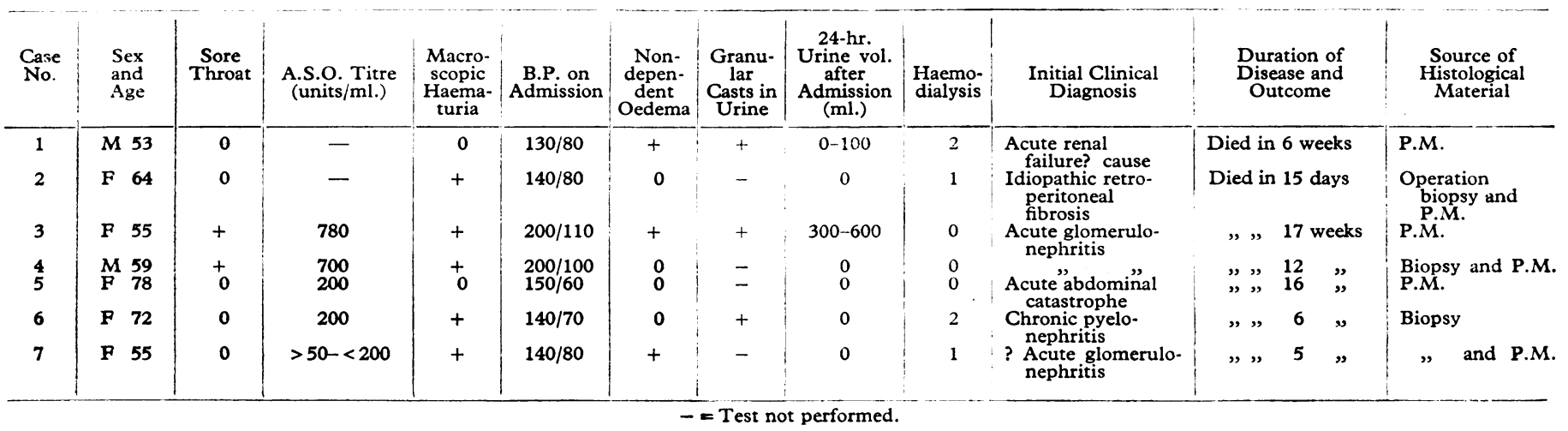


acute glomerulonephritis. Samiy et al. (1961) described seven cases of patients aged over 60 with acute glomerulonephritis, and three of them died.

There appear to be three types of histological lesion accompanying the clinical picture seen in our patients: (1) a predominantly proliferative and exudative lesion, which is regarded as characteristic of a post-streptococcal glomerulonephritis ; (2) a predominantly capsular lesion, a capsulitis (Berlyne and Baker, 1964) ; and (3) fibrinoid necrosis which either partially or totally involves the glomerulus. The later two types of renal lesion may follow a streptococcal infection but more commonly are found in those acute-glomerulonephritis patients without evidence of such an infection. Some cases present histological appearances which comprise features of all three main types.

Jennings and Earle (1961) have described the "typical" lesion in post-streptococcal glomerulonephritis as a lesion confined to the glomerular tufts and consisting of endothelial proliferation and glomerular exudate. Two of our cases (Nos. 3 and 4) with good evidence of a recent streptococcal infection showed this typical lesion.

The capsular lesion, which is particularly associated with severe oliguria or anuria, was well shown in Cases 5 and 6 , where marked capsular epithelial proliferation resulted in compression or obliteration of glomeruli and even extended down the tubules. This lesion differs from the usual crescent formation in progressive type I glomerulonephritis in that there is complete obliteration of Bowman's space and compression of the vascular tuft. This capsulitis may result from altered immune responses or hypersensitivity reactions, which may involve any part of the nephron basement membrane (Berlyne and Baker, 1964) and is not confined to any particular age group.

The third type of histological change represented by fibrinoid necrosis was found in Cases 2 and 7. The presence of extensive areas of fibrinoid necrosis in the glomeruli indicates a poor prognosis, which is invariably fatal when coupled with capsular epithelial proliferation (Brun, Gormsen, Hilden, Iversen, and Raaschou, 1958 ; Alwall, Erlanson, Tornberg, Fajers, and Moëll, 1958 ; Berlyn and Baker, 1964 ; Harrison et al., 1964). Nine fatal adult cases with necrotizing glomerulitis as the main feature of their acute oliguric glomerulonephritis were reported by Bialestock and Tange (1959). Hypertension did not play any part in the causation of the glomerular necrosis in our patients, their blood-pressure remaining normal, or very nearly so, throughout their illness. Indeed, there was no correlation between the degree of glomerular damage and the presence or absence of a diastolic hypertension in our cases, a finding similar to that of Berlyne and Baker (1964). In a larger series Jennings and Earle (1961) found that diastolic hypertension was more common among patients with severe glomerular damage but commented that there were notable exceptions.
The combination of a marked capsulitis with severe fibrinoid necrosis of the glomerular tuft not only makes recovery impossible but even precludes the onset of a partial diuresis. However, a partial diuresis is possible in the presence of severe endothelial proliferation even with focal areas of fibrinoid necrosis, although the eventual outcome is fatal.

Severe glomerular damage was usually accompanied by tubular damage, and both our examples of necrotizing glomerulitis (Cases 2 and 7) have marked proximal tubular destruction. Similar appearances occur in hypersensitivity nephritis, where any part of the nephron basement membrane may be affected, as seen in drug-sensitivity nephritis (Baker and Williams, 1963 ; Lee and Holden, 1964). All cases showed tubules packed with red cells suggestive of frank haemorrhage, yet red cells were seldom seen in Bowman's space. Hyaline casts featured in all cases, including the definite post-streptococcal ones, where their presence is uncommon (Jennings and Earle, 1961). A generalized or focal cellular infiltrate was present in all cases and included numerous eosinophils in Case 1.

Percutaneous renal biopsy material was obtained in four patients. Since the renal changes in glomerulonephritis are thought to be uniform, this technique allows for a representative sample of tissue to be examined for diagnostic and prognostic purposes. In this, as in other series, there has been a good correlation between clinical and histopathological findings, and biopsy findings have all been confirmed by subsequent post-mortem studies. Repeated, unavailing dialysis can thus be avoided in patients where recovery of renal function cannot be expected.

Prolonged oliguria or anuria in acute glomerulonephritis carries an extremely grave prognosis, particularly in the adult (Merrill, 1957), but recovery has occasionally been reported (Persoff, 1965 ; Nakamoto, Dunea, Kolff, and McCormack, 1965). The renal lesions in those cases that have recovered have been far less severe than reported here or elsewhere (Berlyne and Baker, 1964 ; Harrison et al., 1964). It has been suggested that the typical post-streptococcal type of renal lesion in association with a raised A.S.O. titre warrants persevering with dialysis treatment, but even here the longest period of oliguria with survival was 30 days (Nakamoto et al., 1965). In the absence of a renal biopsy showing features known to preclude recovery of renal function, it seems reasonable to maintain patients with acute oliguric glomerulonephritis by repeated dialysis for at least six weeks and so allow time for a possible spontaneous recovery (Lancet, 1964).

The role of steroids in the management of acute cliguric glomerulonephritis is far from clear. They were found ineffective in eight cases of acute anuric glomerulonephritis (Berlyne and Baker, 1964), as in our only case where used, while elsewhere it has been suggested that they help to promote a diuresis (Nakamoto et al., 1965). However, the two groups of patients

TABLB II.-Details of Renal Histology in 7 Patients with Fatal Acute Glomerulonephritis

\begin{tabular}{|c|c|c|c|c|c|c|}
\hline $\begin{array}{l}\text { Case } \\
\text { No. }\end{array}$ & Material & Type of Lesion & Glomerulus & Capsule & Tubules & $\begin{array}{l}\text { Interstitial } \\
\text { Tissue }\end{array}$ \\
\hline 1 & Necropsy & $\begin{array}{l}\text { Proliferative glomerulo- } \\
\text { nephritis }\end{array}$ & $\begin{array}{l}\text { Epithelial and endothelial } \\
\text { proliferation. Leucocytic }\end{array}$ & - & $\begin{array}{l}\text { Epithelial degeneration. } \\
\text { Casts and red blood cells }\end{array}$ & Cellular infiltrate \\
\hline 2 & Biopsy (Fig. 1)* & $\begin{array}{l}\text { Necrotizing glomerulo- } \\
\text { nephritis }\end{array}$ & $\begin{array}{l}\text { Fibrinoid necrosis and cel- } \\
\text { lular proliferation. Swol. } \\
\text { len necrotic glomeruli } \\
\text { joined to form giant } \\
\text { strectures }\end{array}$ & Necrosis & $\begin{array}{l}\text { Epithelial degeneration and } \\
\text { necrosis. Numerous red } \\
\text { blood cells. Casts }\end{array}$ & $\begin{array}{l}\text { Oedema. Cello- } \\
\text { lar infiltrate }\end{array}$ \\
\hline 3 & Necropsy (Fig. 2) & $\begin{array}{l}\text { Proliferative glomerulo- } \\
\text { nephritis }\end{array}$ & $\begin{array}{l}\text { Endothelial proliferation. } \\
\text { Leucocytic infiltrate }\end{array}$ & Onaras & Red blood cells and casts & Cellular infiltrate \\
\hline $\begin{array}{l}4 \\
5\end{array}$ & Biopsy & $\begin{array}{l}\text { Glomerulonephritis" in } \\
\text { which the predominant } \\
\text { lesion is capsular }\end{array}$ & $\begin{array}{c}\text { Compressed "atrophied" } \\
\text { glomeruli }\end{array}$ & $\begin{array}{l}\text { Occasional crescent } \\
\text { Proliferation of capsular } \\
\text { epithelium }\end{array}$ & $\begin{array}{l}\text { Ep"'thelïal degeneration". } \\
\text { Haemorrhage and casts }\end{array}$ & $"$. \\
\hline 6 & , (Fig. 3) & " " " & " & $\begin{array}{l}\text { Proliferation of capsular } \\
\text { epithelium extending } \\
\text { into the first part of the } \\
\text { tubule }\end{array}$ & $" \quad$ " & \\
\hline 7 & & $\begin{array}{l}\text { Necrotizing glomerulo } \\
\text { nephritis }\end{array}$ & Necrosis of glomeruli & Necrosis & $\begin{array}{l}\text { Epithelial degeneration and } \\
\text { necrosis. Red blood cells } \\
\text { and casts }\end{array}$ & $\begin{array}{l}\text { Marked cellular } \\
\text { infiltrate }\end{array}$ \\
\hline
\end{tabular}


were not comparable, having widely differing renal histology. The use of steroids in this situation must remain an open question.

\section{Summary}

Seven patients with fatal acute glomerulonephritis referred to a haemodialysis unit in a three-year period were between 53 and 78 years of age. The presenting features and natural history of acute glomerulonephritis in this age group of ten differ from those commonly seen in younger patients. The rarity of the disease in the middle-aged and elderly, coupled with the atypical presentation of most of the patients, made the clinical diagnosis difficult.

The histological changes included necrosis of glomerular tufts, obliteration of Bowman's space by proliferation of the capsular epithelium, and endothelial proliferation with glomerular exudate. Renal biopsy is valuable in both establishing the diagnosis and assessing the severity of the disease, and so avoiding submission of patients with no hope of recovery to unnecessary treatment.
We are grateful to Professor J. Anderson for permission to report these cases, and to Professor H. A. Magnus for his advice. The photomicrographs were prepared by Mr. George Harwood.

\section{REFERENCES}

Alwall, N., Erlanson, P., Tornberg, A., Fajers, C. M., and Moëll, H. (1958). Acta med. scand., 161, 85 .

Baker, S. B. de C., and Williams, R. T. (1963). Brit. med. 7., 1, 1655.

Berlyne, G. M., and Baker, S. B. de C. (1964). Quart. F. Med., 33, 105. Bialestock, D., and Tange, J. D. (1959). Aust. Ann. Med., 8, 281 .

Brun, C., Gorsmen, H., Hilden, T., Iversen, P., and Raaschou, F. (1958). Acta med. scand., 160, 155 .

Ellis, Acta med. (1942). Lancet, 1,1 .

Fishberg, A. M. (1954). Hypertension and Nephritis, 5th ed., p. 542. Lea and Febiger, Philadelphia.

Harrison. C. V., Loughridge, L. W., and Milne, M. D. (1964). Quart. 7. Med., 33, 39 .

Jennings, R. B., and Earle, D. P. (1961). 7. clin. Invest., 40, 1525.

Lancet, 1964, 1, 1429.

Lee, H. A., and Holden, C. E. A. (1964). Postgrad. med. 7., 40, 326. Merrill, J. P. (1957). f. chron. Dis., 5, 138

Nakamoto, S., Dunea, G., Kolff, W. J., and McCormack, L. J. (1965). Ann, intern. Med. 63 , Kolff,

Nesson, R. M.. and Robbins, S. L. (1960). Arch. intern. Med., 105, 23. Persoff, D. (1965). Lancet, 1, 347.

Samiy, A. H., Field, R. A., and Merrill, J. P. (1961). Ann. intern. Med. 54,603 .

\title{
Yersinia enterocolitica (Pasteurella X) in Human Enteric Infections
}

\author{
STEN WINBLAD,* M.D. ; BIRGITTA NILEHN,* M.D.; NILS H. STERNBY,† M.D.
}

[With Special Plate]

Brit. med. F., 1966, 2, 1363-1366

The aetiological factors in the acute inflammation of the ileocaecal region-appendicitis, terminal ileitis, and mesenteric lymphadenitis-are poorly understood, but the microflora in these conditions has recently received increasing attention.

In 1954 Knapp and Masshoff found Yersinia pseudotuberculosis (syn. Pasteurella pseudotuberculosis) in inflamed mesenteric lymph nodes. Since then several authors (Knapp and Steuer, 1956 ; Kiaer, 1960 ; Knapp, 1963 ; Mollaret, 1960, 1962 ; Knapp and Thal, 1963) have thoroughly described the bacteriology, serology, and histopathology of Masshoff's disease-that is, mesenteric lymphadenitis caused by $Y$. pseudotuberculosis. In $1957 \mathrm{Kjellén}$ et al. isolated adenovirus from inflamed mesenteric lymph nodes in patients with acute abdominal disease. They also observed rising antibody titres against this virus. Similar observations have been made by Hannoun et al. (1961). Carlsson, Ryd, and Sternby (1964), in this hospital, reported the finding of Yersinia enterocolitica (syn. Pasteurella $X$ ) in a mesenteric lymph node from a patient with acute terminal ileitis and mesenteric lymphadenitis but an apparently normal appendix. Agglutinating antibodies against the patient's own strain developed.

So far as we know $Y$. enterocoiitica has been isolated from man only three times previously-that is, in two cases describcd by Hässig, Karrer, and Pusterla (1949) and in one case described by Mollaret (1965), where the bacterium was isolated by Wyler. The taxonomic position of the Bacterium enterocoliticum strains described by Schleifstein and Coleman (1939) seems, however, still to be questionable.

The occurrence of $Y$. enterocolitica in animals-chinchillas, hares, pigs, and dogs-is well known (Dickinson and Mocquot,

* Institute of Clinical Bacteriology, University of Lund, General Hospital, Malmö, Sweden.

t Institute of Clinical Pathology, University of Lund, General Hospital,
1961 ; Becht, 1962 ; Daniéls and Goudzwaard, 1963 ; Daniéls, 1963 ; Akkermans and Terpstra, 1963 ; Knapp and Thal, 1963 ; Mollaret and Chevalier, 1964 ; Mollaret and Lucas, 1965). The name Yersinia enterocolitica was proposed by Frederiksen (1964).

The finding of $Y$. enterocolitica in this department prompted us to start an investigation of its occurrence in human beings. This report is based on the preliminary results of serological studies on various groups of patients and healthy persons, tested for agglutinins against $Y$. enterocolitica; some groups were also tested for agglutinins against $Y$. pseudotuberculosis type I. Preliminary bacteriological and histopathological data are also included.

\section{Methods and Material}

\section{Antigen Preparation}

The $Y$. enterocolitica antigens for routine agglutination tests were prepared from strain "Winblad," isolated from the case described by Carlsson et al. (1964). Antigens were also preparcd from the following $Y$. enterocolitica strains of chinchilla, canine, and human origin: Siegmann 268 ; Daniéls 975, 905, 924, 931 ; Becht 18, 51, 200 ; Frederiksen P 71 ; Hässig (homo). O antigen from these strains and from strain Winblad gave the same results with positive patient sera and rabbit antisera prepared against strain Winblad in all cases except one (strain Frederiksen $\mathrm{P}$ 71).

$O$ Antigen.-Human blood-agar plates were seeded with the $S$ form of the strain and were incubated for 48 hours at $22^{\circ} \mathrm{C}$. The culture was collected in saline, washed, and autoclaved at $120^{\circ}$ C. for two and a half hours. It was then washed repeatedly and suspended in saline for the use in tube agglutination. 


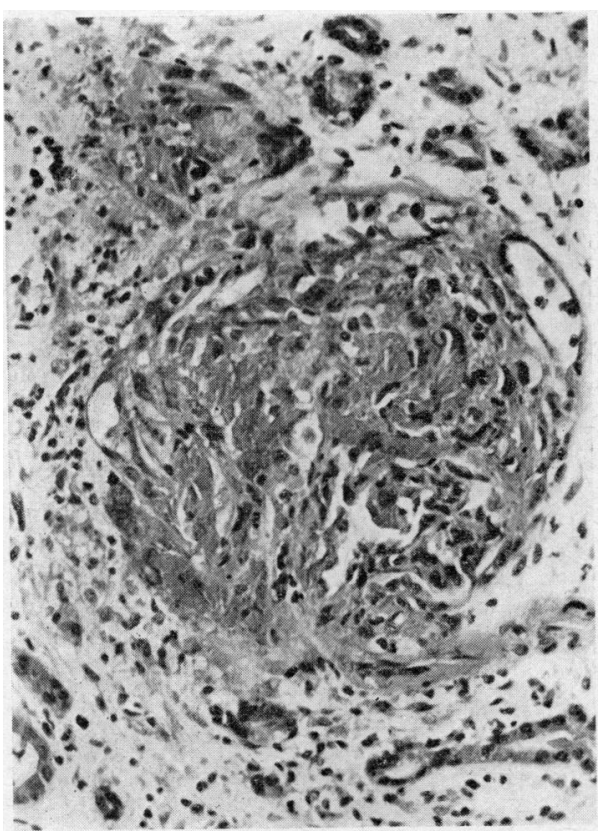

FIG. 1.-Case 2. Necrotizing glomerulonephritis. (H. and E. $\times 260$.)
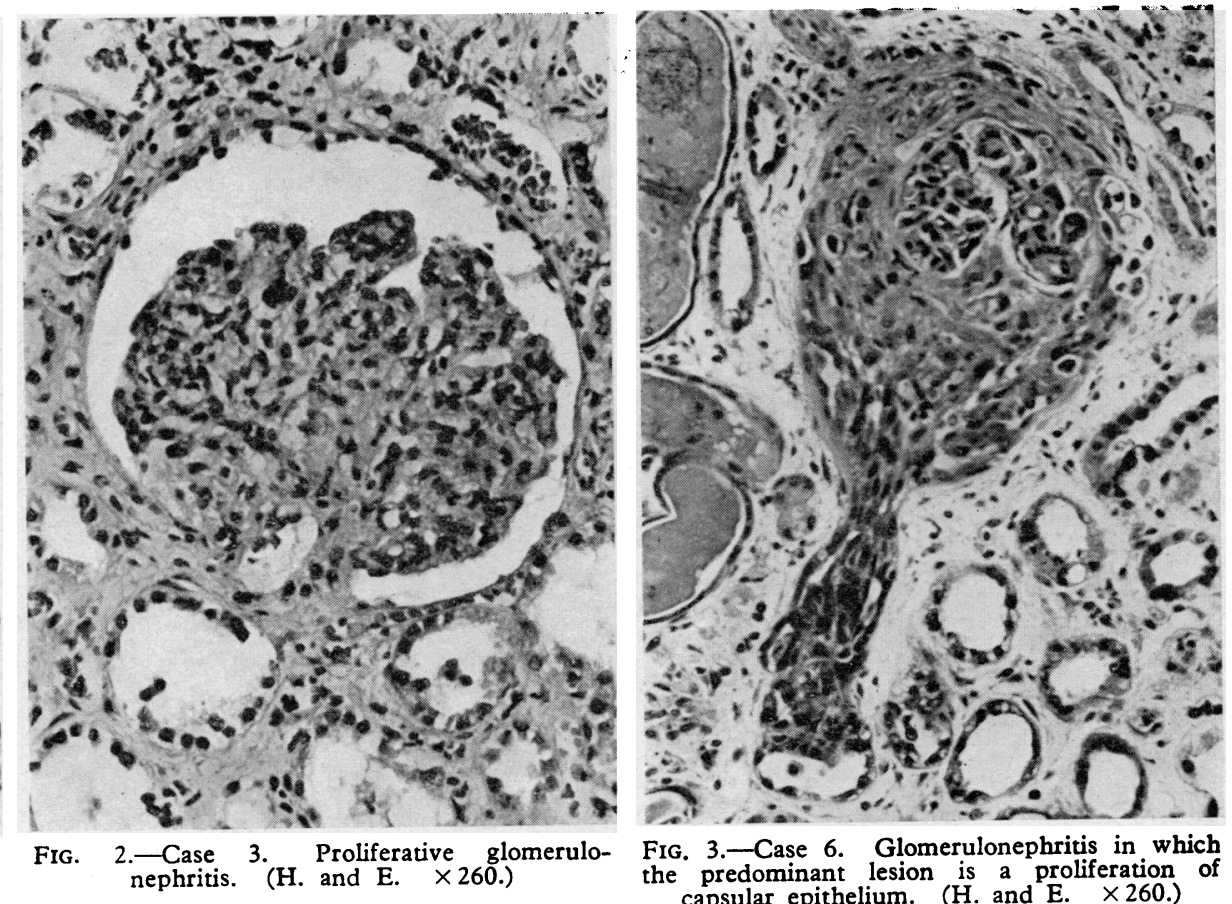

FIG. 3-Case 6. Glomerulonephritis in which the predominant lesion is a proliferation of capsular epithelium. (H. and E. $\times 260$.)

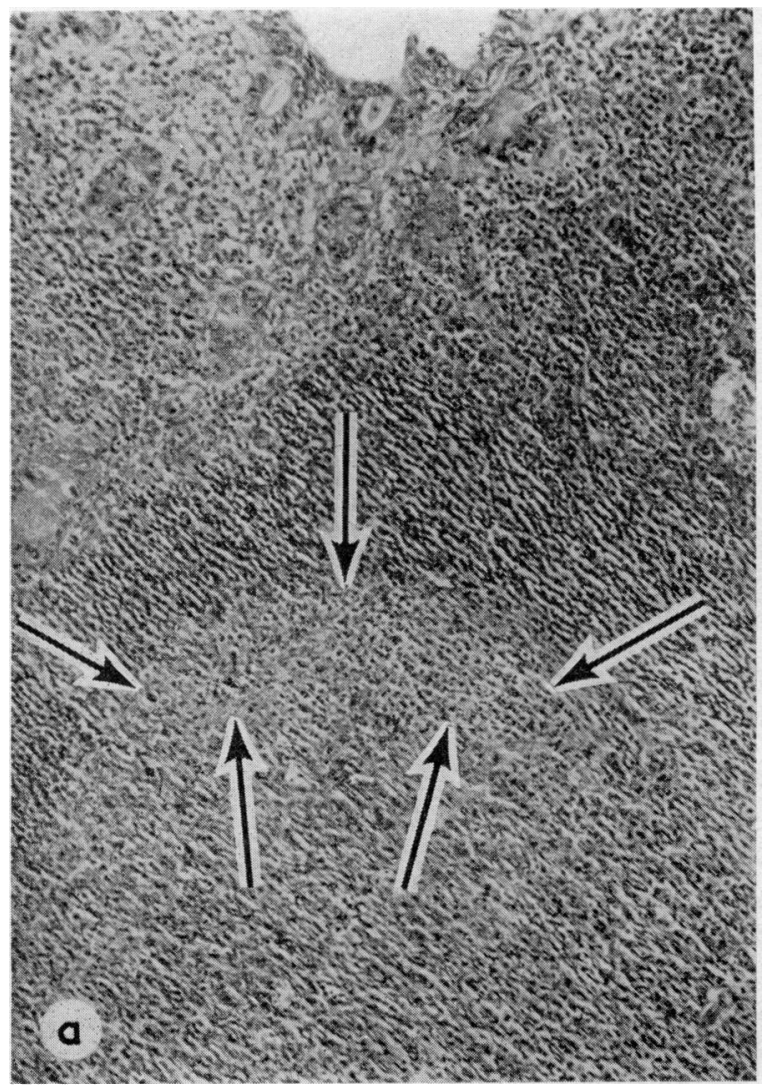

Fig 4--Sections from the wall of the appendix in two cases of $Y$. enterocolitica infection. In the germinal centre small collections of leucocytes (microabscesses) are seen. Haematoxylin-eosin staining. (a) $\times 120$. (b) $\times 192$.

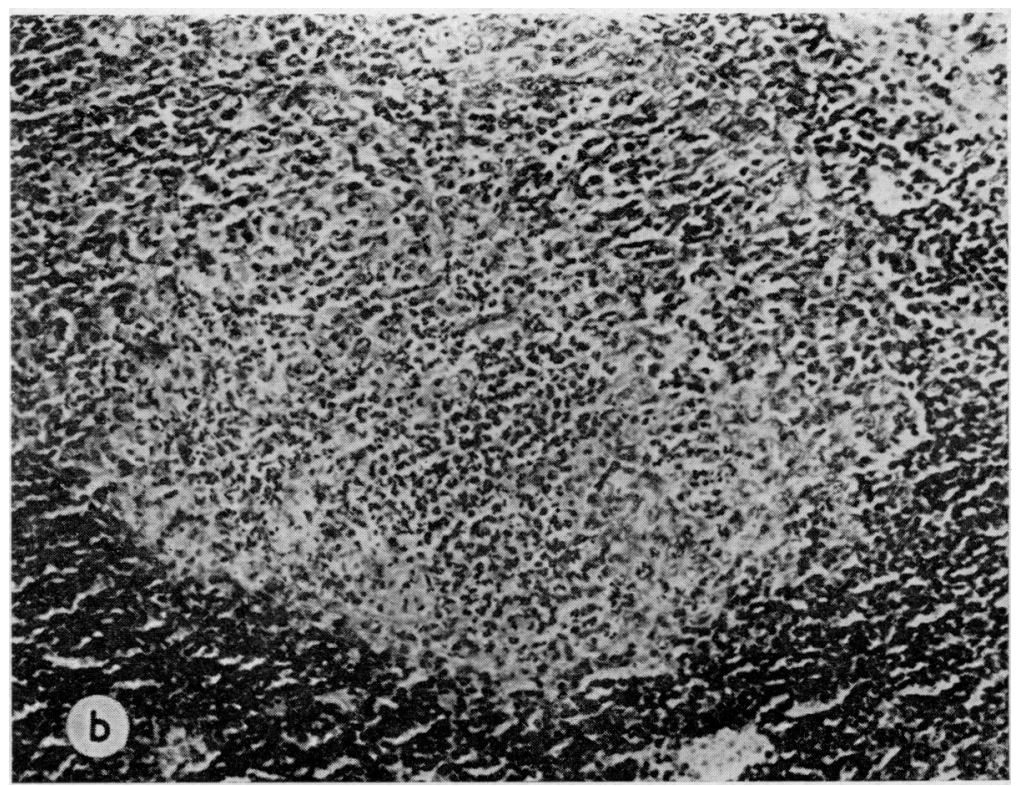

